\title{
Familial Pancreatic Cancer
}

Gloria M. Petersen, Ph.D.

Department of Health Sciences Research, Mayo Clinic Cancer Center, Rochester, Minnesota

\begin{abstract}
Familial pancreatic cancer (FPC) includes those kindreds that contain at least two first degree relatives with pancreatic ductal adenocarcinoma. At least twelve known hereditary syndromes or genes are associated with increased risk of developing pancreatic cancer, the foremost being $B R C A 2$ and $C D K N 2 A$. Research into the identification of mutations in known cancer predisposition genes and through next generation sequencing has revealed extensive heterogeneity. The development of genetic panel testing has enabled genetic risk assessment and predisposition testing to be routinely offered. Precision oncology has opened the possibility of "incidental" germline mutations that may have implications for family members. However, in both cases, evidence-based recommendations for managing patients and at-risk family members in light of genetic status remain emergent, with current practice based upon expert opinion.
\end{abstract}

Among the major cancers, pancreatic cancer has the worst survival and historically has been the least studied. In 2016, there will be an estimated 53,070 new cases and 41,780 deaths due to pancreatic cancer in the United States ${ }^{1}$. The absolute number of new cases and deaths ascribed to pancreatic cancer has been increasing steadily since 2004, largely due to the "baby-boomer" generation reaching the risk window ${ }^{2}$, for which the median age at diagnosis is 71 years. It has been predicted that by 2030, pancreatic cancer will be the second most common cause of cancer mortality, after lung cancer ${ }^{3}$. Approximately $95 \%$ of pancreatic neoplasms are ductal adenocarcinomas, and represent the most challenging to treat. The rapid mortality of patients with pancreatic cancer has also made this neoplasm challenging for research. Along with recent technological advances that facilitate better understanding of its genetic etiology, investigations of pancreatic cancer families have provided the first substantive insights. Combined with increasing focus on precision oncology, it is inevitable that more attention will be given to germline genetic variation and its clinical implications.

\section{Definition and Epidemiology of Familial Pancreatic Cancer}

Familial pancreatic cancer (FPC) ${ }^{4}$ is defined as a kindred which contains at least a pair of first degree relatives who were affected with pancreatic adenocarcinoma. Approximately 510 per cent of patients with pancreatic adenocarcinoma fit this criterion ${ }^{5}$. This standardized definition is now widely used; it has facilitated research addressing a variety of questions, including genetic susceptibility. An early analysis of FPC kindreds by the Pancreatic Cancer

Corresponding author: Gloria M. Petersen, Ph.D., Department of Health Sciences Research, Mayo Clinic, Charlton 6-243, Rochester, MN 55905, Petersen.gloria@mayo.edu, Telephone: (507) 538-1563, Fax: (507) 266-2478.

The author has no conflicts of interest or disclosures 
Genetic Epidemiology (PACGENE) Consortium ${ }^{6}$ found that half of FPC probands are male, and the mean age at diagnosis of affected members is younger (64 to 65 years) than expected compared to sporadic pancreatic cancer patients as estimated by Surveillance, Epidemiology and End Results (SEER) ${ }^{7}$. Further, the PACGENE study found that mean ages at diagnosis did not significantly differ when stratified by number of affected individuals in the pedigree (i.e., the age at diagnosis did not decrease with increasing number of affected individuals in the kindred).

The original evidence supporting the hypothesis that some proportion of pancreatic cancer might have a genetic basis was drawn from observations of familial clustering and hereditary syndromes that featured increased risk of pancreatic cancer. Early reports of clusters of pancreatic cancer in families provided the first suggestion that a least a hereditary, but rare form of pancreatic cancer might exist. Reports of clusters included families in which multiple siblings were affected (but not the parents) (e.g., ${ }^{8,9}$ ) or one family where each of three generations contained an affected member ${ }^{10}$. These observations were bolstered by familial aggregation studies using epidemiologic study designs that consistently showed increased risk of pancreatic cancer in relatives of cases with pancreatic cancer compared to healthy controls, with odds ratios over multiple studies averaging around 3 , and slightly lower relative risks in cohort studies (Table 1). These ten case control studies, two cohort studies, one population-based genealogic analysis, and one case series that estimated incidence of pancreatic cancer in relatives, are congruent overall. This is despite variation in types of controls used, case ascertainment methods, data collection that spanned thirty or more years, multiple countries and cultures, and different methods for estimating risk. A systematic review and meta-analysis of a cohort study and seven case-control studies totaling 6,568 pancreatic cancer cases calculated an overall relative risk of 1.80 (95\% CI: $1.48-2.12)^{11}$ This study also found that $1.3 \%$ of pancreatic cancer in the population is attributable to family history. The risk was consistent for both males and females, and did not differ by early or late age at diagnosis. A formal genetic segregation analysis of unselected pancreatic cancer patients' pedigrees found patterns consistent with autosomal dominant inheritance of a rare major susceptibility gene or genes ${ }^{12}$.

With respect to incident risk of pancreatic cancer in the FPC setting, Klein et al. ${ }^{13}$ analyzed 5,179 individuals in 838 FPC kindreds, and quantified risk using standardized incidence ratios (SIR) that compared the number of incident pancreatic cancers observed with those expected using SEER ${ }^{7}$ rates. During the follow-up period from time of enrollment, 19 pancreatic cancers developed among the relatives. The observed-to-expected rate of pancreatic cancer was 9.0 (95\% CI: 4.5-16.1), significantly increased compared to members of kindreds of sporadic pancreatic cancer patients. It was also noted that with increasing number of affected individuals in the pedigree, the risk increased: three affected first degree relatives in the kindred had a SIR=32.0 (95\% CI:10.2-74.7), two affected had a SIR=6.4 (95\% CI: 1.8-16.4), versus one affected had a SIR=4.6 (95\% CI, 0.5-16.4). Compared to the general population incidence of 9 per 100,000, FPC relatives with three affected individuals in the pedigree have an estimated incidence of 288 per 100,000, and for individuals with two affected individuals in the kindred, the incidence is 57.6 per 100,000, and 41.1 per 100,000 if an individual has one affected relative. Similar systematic analyses of risk in relatives for extra-pancreatic cancers in the FPC setting have not been reported. However, while it is 
documented through anecdotal observations of increased risk of other cancers, particularly breast cancer, melanoma, and colorectal cancer, these risks have not been systematically disentangled from considerations of germline mutations in cancer susceptibility genes. In the case of sporadic pancreatic cancer, McWilliams et al. ${ }^{5}$ found increased risk of liver carcinoma ( $\mathrm{SIR}=2.70 ; 95 \% \mathrm{CI}, 1.51-4.46$ ) in first degree family members of 426 probands, and the among younger probands (aged 60 years or less at diagnosis), first degree relatives had borderline increased risks of melanoma (SIR=1.73; 95\% CI, 0.70-3.57), ovarian carcinoma (SIR=2.20; 95\% CI, 0.72-5.12), and colon carcinoma (SIR=1.37; 95\% CI, 0.802.19). Taken together, the observed family history evidence across the different studies supports genetic heterogeneity of FPC.

It remains unclear whether or how lifestyle factors influence pancreatic cancer risk among FPC family members. Cigarette smoking is a well-established risk factor for sporadic pancreatic cancer. A pooled case-control study that included 6,507 cases with pancreatic cancer found that the prevalence of never-smokers was $36.5 \%$ and $60.5 \%$ for ever-smokers, with $2.6 \%$ missing or other ${ }^{14}$. In the PACGENE study, $37 \%$ of affected members of FPC kindreds were never-smokers, $47.1 \%$ were ever- smokers, but smoking status was unknown in $14.9 \%$ \{Petersen, $2006 \# 11$ \}. In comparison, a regional hospital-based Australian study found that $60.3 \%$ of 68 FPC patients were never smokers compared to $45.6 \%$ never-smokers in 698 non-FPC patients ( $\mathrm{p}=.0315)$. However, there were no differences in alcohol intake in this study ${ }^{15}$. It has been suggested that smoking may potentiate pancreatic cancer risk among predisposition gene mutation carriers ${ }^{16}$, but to date, this has not been possible to fruitfully evaluate. Data on other pancreatic cancer risk factors, such diet or obesity, are too sparse among FPC to draw meaningful inferences. Similarly, disease associations, such as diabetes or pancreatic cyst disease, have not been systematically studied in the context of FPC.

\section{Genetics of Familial Pancreatic Cancer}

The genetic basis of pancreatic cancer and FPC has been extensively investigated over the past decade, and findings have been substantially summarized in recent reviews ${ }^{17-19}$. The goals of most studies that would have timely clinical translation have been the identification of high penetrance susceptibility genes and characterization of their deleterious mutations. Increased risk of pancreatic cancer is now known to be associated with several inherited syndromes for which the predisposing genes have been identified, including BRCA1, $B R C A 2, C D K N 2 A$, mismatch repair genes associated with Lynch syndrome, and hereditary pancreatitis-related genes, PRSS1 and SPINK2. The identification of germline mutations in $P A L B 2$ and $A T M$ among FPC probands using next-generation sequencing has extended the list of predisposing genes. In the case of $P A L B 2$ and $A T M$, functional roles for identified germline mutations were supported by the loss of heterozygosity of the wild-type allele in the pancreatic tumor of the patients. In the course of complete exome sequencing of unselected pancreatic cancer patients, Jones et al. ${ }^{20}$ identified a germline truncating mutation in PALB2 that co-segregrated in an FPC kindred. This led to screening the DNA of 96 more FPC patients specifically for $P A L B 2$ mutations. Truncating mutations were detected in three additional patients, however no difference was observed in age at diagnosis of the mutation carriers. No PALB2 mutations were found in 1,084 normal controls. Similarly, mutations in 
the ataxia telangiectasia mutated ( $A T M)$ gene were found to co-segregate with the pancreatic cancer phenotype in two FPC kindreds by Roberts et al. ${ }^{36}$ The investigators screened the ATM gene for mutations in DNA of 166 FPC patients, and identified four carriers of deleterious mutations. No similar mutations were seen in 190 controls.

Subsequent to these discoveries, studies of mutation analysis in FPC patient series for these genes have been published. The syndromes and genes associated with predisposition to pancreatic cancer are summarized in Table 2, along with associated malignancies, and estimates of risk. The most prominent syndromes are hereditary breast-ovarian cancer syndrome, particularly due to germline mutations in $B R C A 2$, and familial atypical mole and melanoma syndrome, due to mutations in $C D K N 2 A$, which encodes the well-known tumorigenic protein, $\mathrm{p} 16$. The most comprehensive analysis to characterize the genetic variation in FPC patients tested across four genes was performed by Zhen et al. ${ }^{21}$. In this PACGENE Consortium study, germline DNA of 727 unrelated probands with positive family history (521 met criteria for FPC) were tested for mutations in BRCA1, BRCA2, $P A L B 2$, and $C D K N 2 A$, and prevalence estimated. Among FPC probands, prevalences were: $B R C A 1,1.2 \% ; B R C A 2,3.7 \% ; P A L B 2,0.6 \%$; and $C D K N 2 A, 2.5 \%$. The probability of testing positive for deleterious mutations in any of the four genes ranged up to $10.4 \%$, depending upon family history of cancers. BRCA2 and $C D K N 2 A$ account for the majority of mutations in FPC (6\%).

Efforts to characterize genetic mutations have focused on expansion of the genes to be sequenced. In the Ontario Pancreas Cancer Registry study ${ }^{22}$, germline DNA from 290 patients with varying degrees of family history were sequenced using a panel of 13 genes (APC, ATM, BRCA1, BRCA2, CDKN2A, MLH1, MSH2, MSH6, PALB2, PMS2, PRSS1, $S T K 11$, and TP53). While 11 total deleterious mutations were found (three in $A T M$, one in BRCA1, two in BRCA2, one in $M L H 1$, two in $M S H 2$, one in $M S H 6$, and one in TP53, the only mutation detected among 39 FPC patients was one in $A T M$. Due to the variation in family history and FPC status, the aggregate probability of having a positive gene test is $3.8 \%$ in the Ontario study compared to over $10 \%$ in familial subsets in the PACGENE study.

More recently, Chaffee et al. ${ }^{23}$ reported results of sequencing using a 25-cancer gene panel among 303 patients with family history of pancreatic cancer (including all of the Mayo Clinic cases in the PACGENE study, and of which 186 met criteria for FPC). They found gremline mutations in ten genes (ATM, BRCA1, BRCA2, CDKN2A, PALB2, PMS2, $B A R D 1, C H E K 2, M U T Y H$, and $N B N$ ), which accounted for $11.6 \%$ prevalence overall; when restricted to FPC patients, the prevalence was $12.9 \%$.

\section{Novel Gene Discovery Applied to Both Sporadic and Familial Pancreatic Cancer}

The search for novel predisposition genes for FPC has been ongoing. Two main approaches have been pursued: candidate gene analysis and agnostic whole genome/exome sequencing. These approaches have been applied to samples of patients who are apparently sporadic cases, as well as patients who have a family history of pancreatic cancer. 
Gene resequencing studies of single candidate genes have provided estimates of prevalence or implicated genes that increase risk of pancreatic cancer. van der Heijden et al. ${ }^{24}$ identified gene mutations in Fanconi anemia related genes, FANCC and FANCG, among young-onset pancreatic cancer. Rogers et al ${ }^{25,26}$ examined 38 FPC kindreds for Fanconi anemia gene mutations, confirming the role of $F A N C C$ and $F A N C G$, but not FANCA. Couch et al. ${ }^{27}$ screened 421 unselected Mayo Clinic cases for mutations in FANCC and FANCG genes, and found two mutations of FANCC in sporadic young onset patients, but none in FANCG. A different approach was based upon established data that the cystic fibrosis transmembrane regulator $(C F T R)$ gene is associated with chronic pancreatitis, which increases risk of pancreatic cancer. McWilliams et al. ${ }^{28}$ screened 949 unselected White Mayo Clinic pancreatic cancer cases for 39 mutations in CFTR known to be causally related to cystic fibrosis, and compared with data on 13,340 White controls from a clinical laboratory database. They found that $5.3 \%$ carried a common CFTR mutation versus $3.8 \%$ of controls, giving an $\mathrm{OR}=1.40$ (95\% CI: 1.04-1.89). Among patients who were younger when their disease was diagnosed ( $<60$ years), the carrier frequency was higher than in controls and resulting OR increased to 1.82 (95\% CI: 1.14-2.94). McWilliams et al. ${ }^{16}$ also estimated the prevalence of deleterious mutations in $C D K N 2 A$ in a series of 1,537 sporadic, unselected patients, and found a prevalence of $0.6 \%$.

Advances in high-throughput sequencing technology, bioinformatics, and computing capacity have benefited the discovery of high penetrance, low frequency susceptibility genes for pancreatic cancer. As described above, whole exome sequencing of patients with and without family history of pancreatic cancer led to the identification of PALB2 and ATM, which had not been previously known to increase risk of pancreatic cancer. More recently, large numbers of patients, familial and sporadic, are being sequenced for germline mutations. As shown in Table 3, sample sizes have ranged from 11 to 638, and the number of genes for which mutations have been characterized, has ranged from 7 to 513 . The general trend is that as more genes are searched, the higher the overall prevalence of pathogenic mutations found. This is true for both familial and sporadic cases. Indeed, the proportion of sporadic cases who carry mutations is of great interest, and may have translational implications. Moreover, the agnostic gene discovery efforts (such as whole exome or whole genome sequencing) is identifying novel genes, but the prevalence, gene by gene, is quite low, and in many cases are unique to specific individuals.

Research to date has clearly revealed the extensive genetic heterogeneity of the FPC phenotype. In addition to expanding the catalog of genes, they provide an opportunity to study the potential effect of genetic mutations on age at diagnosis and risk of developing other cancers. This remains a fertile area for future researchers to fill in the gaps of our knowledge about the epidemiology, functional, and clinical implications of these reported mutations, such as elaborating the penetrance of mutations (the lifetime probability that a mutation carrier will develop cancer), and potential modifiers of cancer penetrance.

Moreover, the growing body of data suggests that germline mutations are not restricted to patients with a first degree relative with pancreatic cancer or even other cancers, and that the concept of FPC should be broadened to include patients who carry germline pancreatic cancer predisposition mutations, regardless of family history. The emerging trend of multiple 
gene panel testing of patients regardless of family history indications may be a concern, as discussed below.

\section{Clinical Translation of Familial Pancreatic Cancer and Genetic Research}

As has occurred with other genetic analysis of other cancers, the transfer of discoveries to the clinical laboratory and bedside is occurring rapidly. Germline mutation analysis by commercial testing is already offered through genetic testing companies, but recommendations regarding who is appropriate for genetic testing are nascent. While there is a need for more genetic epidemiologic evidence, the aggregate prevalence of mutations in current genetic panels is such that there still remain gaps so that fully informed strategies are not in place to guide patients and their families. Multiple fronts needing evidence-based guidelines have been opened: risk assessment and genetic testing, personalized therapy, screening for earlier detection, and prevention.

Evidence driven research is becoming even more pressing as personalized therapy or precision oncology in the care of cancer patients moves forward with breathtaking speed. Genomic analysis of tumors for informing therapeutic decision-making is rapidly becoming standard of care. In the course of tumor analysis, germline genetic information is also generated, often considered "incidental findings." 29,30 This has exposed new areas for which information, ethical analysis, and guidance are very much needed ${ }^{31,32}$.

\section{Genetic testing and cancer risk assessment}

Susceptibility gene discovery that leads to a genetic testing is a rapid translation of research to clinic. Genetic testing is accompanied by risk assessment and genetic counseling including family history patterns of cancer transmission in the family, along with presence of other cancers, such as breast cancer, colorectal cancer, or malignant melanoma. Family history alone is now sufficient basis for triggering a referral to a cancer genetic counselor. Genetic testing of at-risk individuals, particularly in cancer high risk clinics, is usually considered. As discussed above, the cancer multigene testing panels can be a double-edged sword. Genetic testing can provide more information about genes than was previously known to be relevant; thus while the information yield may be higher, we may still be be hampered in our interpretation for lack of evidence upon which to develop guidelines for the patient or family ${ }^{33-35}$.

\section{Managing high risk individuals}

Screening, surveillance, and management guidelines for genetically high-risk individuals remains an evolving and unsettled area for researchers and clinicians. The most widely used resource to date is the published consensus based on the clinical experiences of 49 experts in the Cancer of the Pancreas Screening (CAPS) Consortium ${ }^{36}$ There was excellent agreement on goals of a screening program (should detect and treat T1N0M0 margin-negative PC and high-grade dysplastic precursor lesions. Candidates for screening include first degree relatives of an affected patient in an FPC kindred, patients with Peutz-Jeghers syndrome, and mutation carriers of FPC hereditary cancer syndrome genes with an affected first degree relative. While initial screening should include endoscopic ultrasonography (EUS) and/or 
MRI/magnetic resonance cholangiopancreatography, the CAPS Consortium could not reach consensus on ages to initiate or stop surveillance, nor on longer term management of problematic scenarios. ${ }^{36}$ This consensus effort underscores the need for more research and collaboration.

The American College of Gastroenterology (ACG) has published its clinical guidelines on genetic testing and management of hereditary gastrointestinal cancer syndromes, including hereditary pancreatic cancer. Agreeing with the CAPS Consortium, surveillance of genetically high risk individuals should be performed in experienced centers with a multidisciplinary approach. The ACG guidelines include a conditional recommendation with low quality of evidence that surveillance for pancreatic cancer should be with EUS and/or MRI annually starting at age 50 years, or 10 years younger than the earliest age of pancreatic cancer in the family. The quality of the supporting data for the guidelines is low and, combined with the experience and caution of others ${ }^{37-39}$, it is important to maintain perspective when counseling high risk relatives. Most recently, Vasen and colleagues have published their experience of screening for pancreatic cancer among genetically high risk individuals and have concluded that screening is warranted for individuals who are known carriers of mutations. ${ }^{40}$

\section{Summary}

FPC kindreds contain at least two first degree relatives with pancreatic ductal adenocarcinoma. Family history analysis and genetic discovery studies of FPC have uncovered important new genes and insights about the genetics of pancreatic cancer. Research to date reveals that a dozen known hereditary syndromes or genes are associated with increased risk of developing pancreatic cancer, the most prominent of which are $B R C A 2$ and $C D K N 2 A$. As can be expected, there exist a constellation of kindreds containing multiple members who have been diagnosed with pancreatic cancer but do not meet the strict research definition of FPC. We are now gaining more clarity on the genetic underpinnings across groups of patients defined by family history status, whether absent (sporadic cases) or present as familial aggregation or hereditary syndromes. Next generation sequencing technologies successfully identified now established FPC genes, PALB2 and $A T M$, and continue to lead to novel susceptibility genes, which now constitute $10-15 \%$ of FPC and sporadic patients. At the same time, with rapid utilization of genomic technologies in both clinical genetics and precision oncology settings, many challenges remain. Genetic testing, management of those at risk, and genomic tumor testsing have proven the need for effective, evidence-based criteria.

\section{Acknowledgments}

Supported in part by NCI grants R01CA97075; P50CA102701

\section{References}

1. Siegel RL, Miller KD, Jemal A. Cancer statistics, 2016. CA Cancer J Clin. Jan; 2016 66(1):7-30. [PubMed: 26742998] 
2. Yancik R, Ries LA. Cancer in older persons. Magnitude of the problem-how do we apply what we know? Cancer. Oct 1; 1994 74(7 Suppl):1995-2003.

3. Rahib L, Smith BD, Aizenberg R, Rosenzweig AB, Fleshman JM, Matrisian LM. Projecting cancer incidence and deaths to 2030: the unexpected burden of thyroid, liver, and pancreas cancers in the United States. Cancer Res. Jun 1; 2014 74(11):2913-2921. [PubMed: 24840647]

4. Hruban RH, Petersen GM, Goggins M, et al. Familial pancreatic cancer. Annals of oncology : official journal of the European Society for Medical Oncology / ESMO. 1999; 10(Suppl 4):69-73.

5. McWilliams RR, Rabe KG, Olswold C, De Andrade M, Petersen GM. Risk of malignancy in firstdegree relatives of patients with pancreatic carcinoma. Cancer. Jul 15; 2005 104(2):388-394. [PubMed: 15912495]

6. Petersen GM, de Andrade M, Goggins M, et al. Pancreatic cancer genetic epidemiology consortium. Cancer Epidemiol Biomarkers Prev. Apr; 2006 15(4):704-710. [PubMed: 16614112]

7. Surveillance E, and End Results Program,. http://seer.cancer.gov/.

8. Ghadirian P, Simard A, Baillargeon J. Cancer of the pancreas in two brothers and one sister. Int J Pancreatol. Oct-Dec;1987 2(5-6):383-391. [PubMed: 3693982]

9. MacDermott RP, Kramer P. Adenocarcinoma of the pancreas in four siblings. Gastroenterology. Jul; 1973 65(1):137-139. [PubMed: 4720820]

10. Ehrenthal D, Haeger L, Griffin T, Compton C. Familial pancreatic adenocarcinoma in three generations. A case report and a review of the literature. Cancer. May 1; 1987 59(9):1661-1664. [PubMed: 3828965]

11. Permuth-Wey J, Egan KM. Family history is a significant risk factor for pancreatic cancer: results from a systematic review and meta-analysis. Familial cancer. 2009; 8(2):109-117. [PubMed: 18763055]

12. Klein AP, Beaty TH, Bailey-Wilson JE, Brune KA, Hruban RH, Petersen GM. Evidence for a major gene influencing risk of pancreatic cancer. Genet Epidemiol. Aug; 2002 23(2):133-149. [PubMed: 12214307]

13. Klein AP, Brune KA, Petersen GM, et al. Prospective risk of pancreatic cancer in familial pancreatic cancer kindreds. Cancer Res. Apr 1; 2004 64(7):2634-2638. [PubMed: 15059921]

14. Bosetti C, Lucenteforte E, Silverman DT, et al. Cigarette smoking and pancreatic cancer: an analysis from the International Pancreatic Cancer Case-Control Consortium (Panc4). Annals of oncology : official journal of the European Society for Medical Oncology / ESMO. Jul; 2012 23(7):1880-1888.

15. Humphris JL, Johns AL, Simpson SH, et al. Clinical and pathologic features of familial pancreatic cancer. Cancer. Dec 1; 2014 120(23):3669-3675. [PubMed: 25313458]

16. McWilliams RR, Wieben ED, Rabe KG, et al. Prevalence of CDKN2A mutations in pancreatic cancer patients: implications for genetic counseling. European journal of human genetics : EJHG. Apr; 2011 19(4):472-478. [PubMed: 21150883]

17. Amundadottir LT. Pancreatic Cancer Genetics. Int J Biol Sci. 2016; 12(3):314-325. [PubMed: 26929738]

18. Klein AP. Genetic susceptibility to pancreatic cancer. Molecular carcinogenesis. Jan; 2012 51(1): 14-24. [PubMed: 22162228]

19. Petersen GM. Familial Pancreatic Adenocarcinoma. Hematol Oncol Clin North Am. Aug; 2015 29(4):641-653. [PubMed: 26226902]

20. Jones S, Hruban RH, Kamiyama M, et al. Exomic sequencing identifies PALB2 as a pancreatic cancer susceptibility gene. Science. Apr 10.2009 324(5924):217. [PubMed: 19264984]

21. Zhen DB, Rabe KG, Gallinger S, et al. BRCA1, BRCA2, PALB2, and CDKN2A mutations in familial pancreatic cancer: a PACGENE study. Genetics in medicine : official journal of the American College of Medical Genetics. Jul; 2015 17(7):569-577. [PubMed: 25356972]

22. Grant RC, Selander I, Connor AA, et al. Prevalence of germline mutations in cancer predisposition genes in patients with pancreatic cancer. Gastroenterology. Mar; 2015 148(3):556-564. [PubMed: 25479140]

23. Chaffee, KG.; McWilliams, R.; Majithia, N., et al. Genetic heterogeneity and survival among pancreatic adenocarcinoma (PDAC) patients with positive family history. Abstract. American Society of Clinical Oncology Annual Meeting; Chicago, IL. 2016. 
24. van der Heijden MS, Yeo CJ, Hruban RH, Kern SE. Fanconi anemia gene mutations in youngonset pancreatic cancer. Cancer Res. May 15; 2003 63(10):2585-2588. [PubMed: 12750283]

25. Rogers CD, Couch FJ, Brune K, et al. Genetics of the FANCA gene in familial pancreatic cancer. Journal of medical genetics. Dec.2004 41(12):e126. [PubMed: 15591268]

26. Rogers CD, van der Heijden MS, Brune K, et al. The genetics of FANCC and FANCG in familial pancreatic cancer. Cancer Biol Ther. Feb; 2004 3(2):167-169. [PubMed: 14726700]

27. Couch FJ, Johnson MR, Rabe K, et al. Germ line Fanconi anemia complementation group C mutations and pancreatic cancer. Cancer Res. Jan 15; 2005 65(2):383-386. [PubMed: 15695377]

28. McWilliams RR, Petersen GM, Rabe KG, et al. Cystic fibrosis transmembrane conductance regulator (CFTR) gene mutations and risk for pancreatic adenocarcinoma. Cancer. Jan 1; 2010 116(1):203-209. [PubMed: 19885835]

29. Catenacci DV, Amico AL, Nielsen SM, et al. Tumor genome analysis includes germline genome: are we ready for surprises? International journal of cancer. Apr 1; 2015 136(7):1559-1567. [PubMed: 25123297]

30. Raymond VM, Gray SW, Roychowdhury S, et al. Germline Findings in Tumor-Only Sequencing: Points to Consider for Clinicians and Laboratories. J Natl Cancer Inst. Apr.2016 108(4)

31. Green RC, Berg JS, Grody WW, et al. ACMG recommendations for reporting of incidental findings in clinical exome and genome sequencing. Genetics in medicine : official journal of the American College of Medical Genetics. Jul; 2013 15(7):565-574. [PubMed: 23788249]

32. Lolkema MP, Gadellaa-van Hooijdonk CG, Bredenoord AL, et al. Ethical, legal, and counseling challenges surrounding the return of genetic results in oncology. Journal of clinical oncology : official journal of the American Society of Clinical Oncology. May 20; 2013 31(15):1842-1848. [PubMed: 23589552]

33. Fendrich V, Langer P, Bartsch DK. Familial pancreatic cancer-status quo. Int J Colorectal Dis. Feb; 2014 29(2):139-145. [PubMed: 23948969]

34. Syngal S, Brand RE, Church JM, Giardiello FM, Hampel HL, Burt RW. ACG clinical guideline: Genetic testing and management of hereditary gastrointestinal cancer syndromes. Am J Gastroenterol. Feb; 2015 110(2):223-262. quiz 263. [PubMed: 25645574]

35. Verna EC, Hwang C, Stevens PD, et al. Pancreatic cancer screening in a prospective cohort of highrisk patients: a comprehensive strategy of imaging and genetics. Clinical cancer research : an official journal of the American Association for Cancer Research. Oct 15; 2010 16(20):50285037. [PubMed: 20876795]

36. Canto MI, Harinck F, Hruban RH, et al. International Cancer of the Pancreas Screening (CAPS) Consortium summit on the management of patients with increased risk for familial pancreatic cancer. Gut. Mar; 2013 62(3):339-347. [PubMed: 23135763]

37. Langer P, Kann PH, Fendrich V, et al. Five years of prospective screening of high-risk individuals from families with familial pancreatic cancer. Gut. Oct; 2009 58(10):1410-1418. [PubMed: 19470496]

38. Templeton AW, Brentnall TA. Screening and surgical outcomes of familial pancreatic cancer. Surg Clin North Am. Jun; 2013 93(3):629-645. [PubMed: 23632149]

39. Brentnall TA. Progress in the Earlier Detection of Pancreatic Cancer. Journal of clinical oncology : official journal of the American Society of Clinical Oncology. Jun 10; 2016 34(17):1973-1974. [PubMed: 27114591]

40. Vasen H, Ibrahim I, Ponce CG, et al. Benefit of Surveillance for Pancreatic Cancer in High-Risk Individuals: Outcome of Long-Term Prospective Follow-Up Studies From Three European Expert Centers. Journal of clinical oncology : official journal of the American Society of Clinical Oncology. Jun 10; 2016 34(17):2010-2019. [PubMed: 27114589]

41. Falk RT, Pickle LW, Fontham ET, Correa P, Fraumeni JF Jr. Life-style risk factors for pancreatic cancer in Louisiana: a case-control study. Am J Epidemiol. Aug; 1988 128(2):324-336. [PubMed: 3394699]

42. Ghadirian P, Liu G, Gallinger S, et al. Risk of pancreatic cancer among individuals with a family history of cancer of the pancreas. Int J Cancer. Feb 20; 2002 97(6):807-810. [PubMed: 11857359] 
43. Fernandez E, La Vecchia C, D’ Avanzo B, Negri E, Franceschi S. Family history and the risk of liver, gallbladder, and pancreatic cancer. Cancer Epidemiol Biomarkers Prev. Apr-May;1994 3(3): 209-212. [PubMed: 8019368]

44. Silverman DT, Schiffman M, Everhart J, et al. Diabetes mellitus, other medical conditions and familial history of cancer as risk factors for pancreatic cancer. Br J Cancer. Aug; 1999 80(11): 1830-1837. [PubMed: 10468306]

45. Inoue M, Tajima K, Takezaki T, et al. Epidemiology of pancreatic cancer in Japan: a nested casecontrol study from the Hospital-based Epidemiologic Research Program at Aichi Cancer Center (HERPACC). Int J Epidemiol. Apr; 2003 32(2):257-262. [PubMed: 12714546]

46. Schenk M, Schwartz AG, O’Neal E, et al. Familial risk of pancreatic cancer. J Natl Cancer Inst. Apr 18; 2001 93(8):640-644. [PubMed: 11309441]

47. Hassan MM, Bondy ML, Wolff RA, et al. Risk factors for pancreatic cancer: case-control study. Am J Gastroenterol. Dec; 2007 102(12):2696-2707. [PubMed: 17764494]

48. Rosato V, Polesel J, Bosetti C, Serraino D, Negri E, La Vecchia C. Population attributable risk for pancreatic cancer in Northern Italy. Pancreas. Mar; 2015 44(2):216-220. [PubMed: 25479588]

49. Austin MA, Kuo E, Van Den Eeden SK, et al. Family history of diabetes and pancreatic cancer as risk factors for pancreatic cancer: the PACIFIC study. Cancer Epidemiol Biomarkers Prev. Oct; 2013 22(10):1913-1917. [PubMed: 23966578]

50. Zheng Z, Zheng R, He Y, et al. Risk Factors for Pancreatic Cancer in China: A Multicenter CaseControl Study. J Epidemiol. 2016; 26(2):64-70. [PubMed: 26441209]

51. Jacobs EJ, Chanock SJ, Fuchs CS, et al. Family history of cancer and risk of pancreatic cancer: a pooled analysis from the Pancreatic Cancer Cohort Consortium (PanScan). Int J Cancer. Sep 1; 2010 127(6):1421-1428. [PubMed: 20049842]

52. Shirts BH, Burt RW, Mulvihill SJ, Cannon-Albright LA. A population-based description of familial clustering of pancreatic cancer. Clinical gastroenterology and hepatology : the official clinical practice journal of the American Gastroenterological Association. Sep; 2010 8(9):812816. [PubMed: 20570637]

53. Roberts NJ, Jiao Y, Yu J, et al. ATM mutations in patients with hereditary pancreatic cancer. Cancer Discov. Jan; 2012 2(1):41-46. [PubMed: 22585167]

54. Iqbal J, Ragone A, Lubinski J, et al. The incidence of pancreatic cancer in BRCA1 and BRCA2 mutation carriers. Br J Cancer. Dec 4; 2012 107(12):2005-2009. [PubMed: 23099806]

55. Goldstein AM, Struewing JP, Fraser MC, Smith MW, Tucker MA. Prospective risk of cancer in CDKN2A germline mutation carriers. Journal of medical genetics. Jun; 2004 41(6):421-424. [PubMed: 15173226]

56. Potjer TP, Kranenburg HE, Bergman W, et al. Prospective risk of cancer and the influence of tobacco use in carriers of the p16-Leiden germline variant. European journal of human genetics : EJHG. May; 2015 23(5):711-714. [PubMed: 25227142]

57. Kastrinos F, Mukherjee B, Tayob N, et al. Risk of pancreatic cancer in families with Lynch syndrome. Jama. Oct 28; 2009 302(16):1790-1795. [PubMed: 19861671]

58. Lowenfels AB, Maisonneuve P, DiMagno EP, et al. Hereditary pancreatitis and the risk of pancreatic cancer. International Hereditary Pancreatitis Study Group. J Natl Cancer Inst. Mar 19; 1997 89(6):442-446. [PubMed: 9091646]

59. Rebours V, Boutron-Ruault MC, Schnee M, et al. Risk of pancreatic adenocarcinoma in patients with hereditary pancreatitis: a national exhaustive series. Am J Gastroenterol. Jan; 2008 103(1): 111-119. [PubMed: 18184119]

60. Giardiello FM, Brensinger JD, Tersmette AC, et al. Very high risk of cancer in familial PeutzJeghers syndrome. Gastroenterology. Dec; 2000 119(6):1447-1453. [PubMed: 11113065]

61. Korsse SE, Harinck F, van Lier MG, et al. Pancreatic cancer risk in Peutz-Jeghers syndrome patients: a large cohort study and implications for surveillance. Journal of medical genetics. Jan; 2013 50(1):59-64. [PubMed: 23240097]

62. Resta N, Pierannunzio D, Lenato GM, et al. Cancer risk associated with STK11/LKB1 germline mutations in Peutz-Jeghers syndrome patients: results of an Italian multicenter study. Dig Liver Dis. Jul; 2013 45(7):606-611. [PubMed: 23415580] 
63. Smith AL, Alirezaie N, Connor A, et al. Candidate DNA repair susceptibility genes identified by exome sequencing in high-risk pancreatic cancer. Cancer Lett. Jan 28; 2016 370(2):302-312. [PubMed: 26546047]

64. Roberts NJ, Norris AL, Petersen GM, et al. Whole Genome Sequencing Defines the Genetic Heterogeneity of Familial Pancreatic Cancer. Cancer Discov. Feb; 2016 6(2):166-175. [PubMed: 26658419]

65. Hu C, Hart SN, Bamlet WR, et al. Prevalence of Pathogenic Mutations in Cancer Predisposition Genes among Pancreatic Cancer Patients. Cancer Epidemiol Biomarkers Prev. Jan; 2016 25(1): 207-211. [PubMed: 26483394]

66. McKay, S.; Humphris, J.; Johns, A., et al. Assessment of germline cancer predisposition genes in 392 unselected pancreatic cancer patients. Abstract. AACR Special Conference on Pancreatic Cancer; May 12-15, 2016; Orlando, FL.

67. Seifert BA, O’Daniel JM, Amin K, et al. Germline Analysis from Tumor-Germline Sequencing Dyads to Identify Clinically Actionable Secondary Findings. Clinical cancer research : an official journal of the American Association for Cancer Research. Apr 15.2016

68. Schrader KA, Cheng DT, Joseph V, et al. Germline Variants in Targeted Tumor Sequencing Using Matched Normal DNA. JAMA Oncol. Jan; 2016 2(1):104-111. [PubMed: 26556299] 


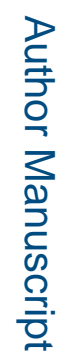

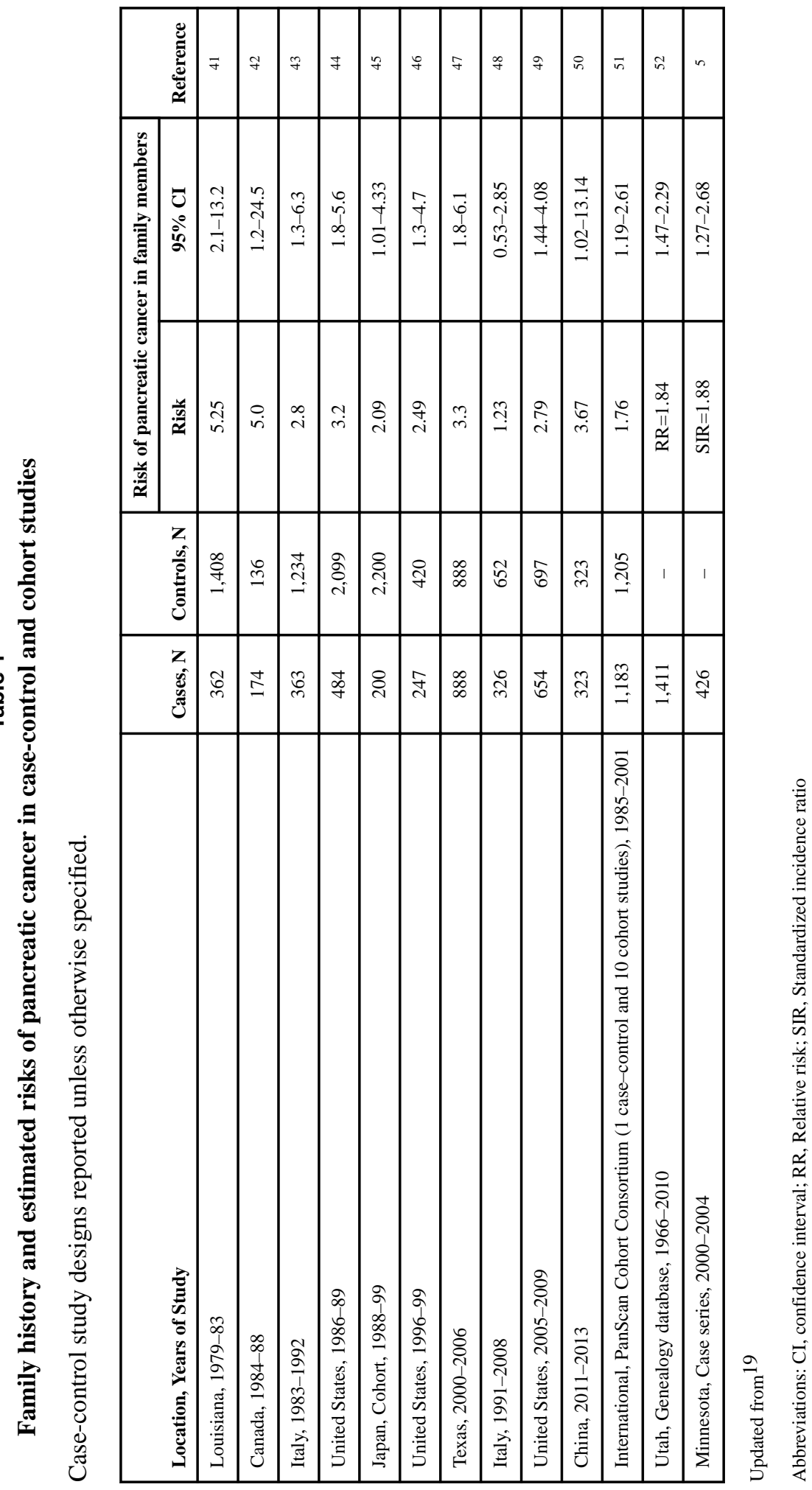

$\frac{2}{2+2}$

Semin Oncol. Author manuscript; available in PMC 2017 January 13. 


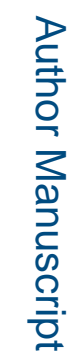

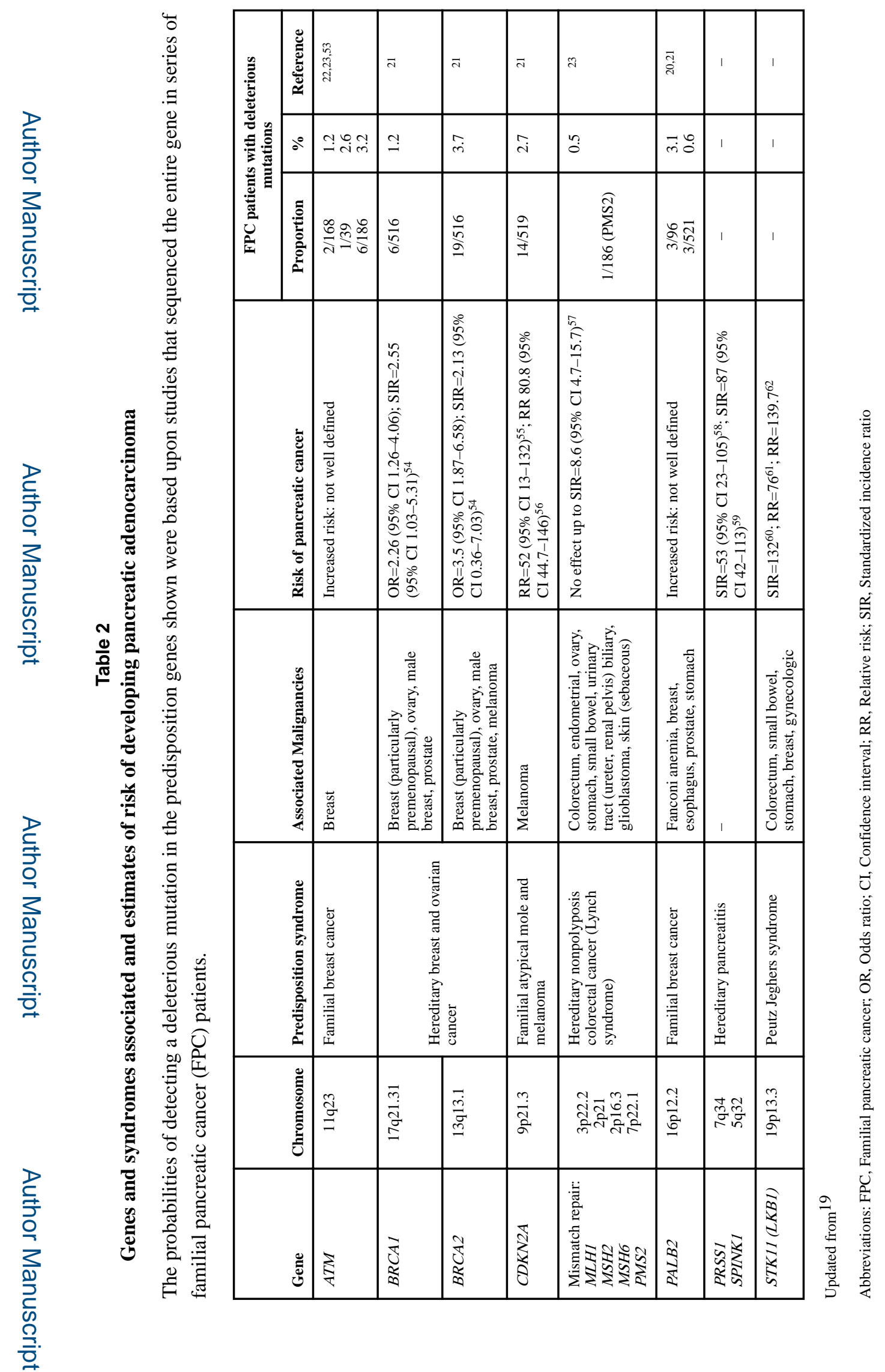

Semin Oncol. Author manuscript; available in PMC 2017 January 13. 


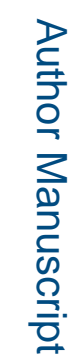

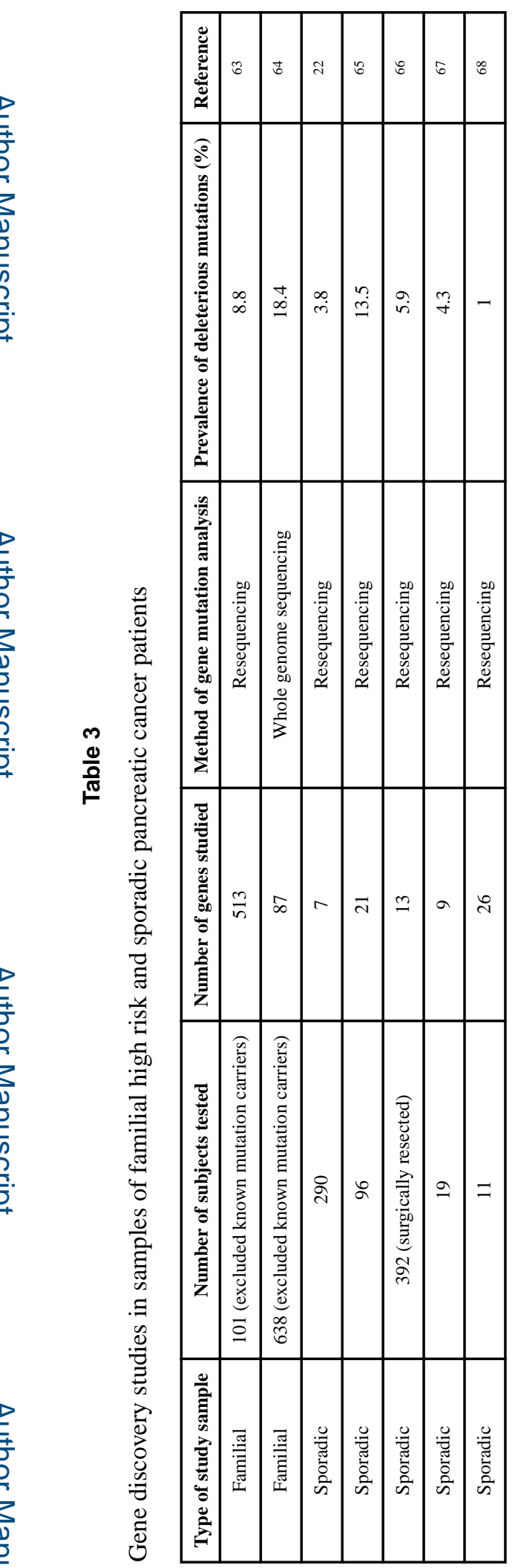

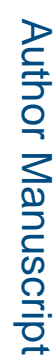



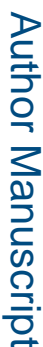

Semin Oncol. Author manuscript; available in PMC 2017 January 13 